\title{
Don Alvaro de Ibarra y la Universidad de San Marcos a mediados del siglo XVII.
}

Uno de los retratos en la galería de la Universidad de San Marcos conserva su figura. Severa la actitud, el vestido negro, la mano izquierda enguantada sosteniendo unos papeles, la derecha desnuda apoyada sobre una mesa con un tapete rojo, cerca de la mitra del obispado de Trujillo. Pero la piel cobriza, la formaz cono cae sobre la frente el tupido cabello negro, los ojosilmendrados y hasta el bigote y la harba ralos, delatan al mestizo.

Don Alvaro de Ibarra nació en Lima, hacia I620. Memoriales adversos a él, enviados a la Corte española refieren que su padre ejercía el oficio de tintorero. Consta, sin embargo, por otro lado, que fueron sus padres don Gregorio de Ibarra, receptor y tesorero de la Inquisición de Lima, y doña Isabel de Carrión. Es cierto, en cambio, que la miseria le acompañó en su infancia y en su juventud. El mismo declaró varias veces que había sido tan pobre que a no estar a las expensas del doctor don Esteban de Ibarra, su hermano, racionero de esta Iglesia, no hubiera podido seguir las escuelas. 
El colegio de San Martín fué su albergue. Estuvo allí de colegial durante diez y ocho años. Se distinguió tanto en los estudios como en los grados, llegando a presidir muchos actos literarios. Optó por la carrera eclesiástica, seguida también, como se ha visto, por su hermano Esteban que llegó a ser canónigo de la iglesia de Lima y comisario general de la Santa Cruzada.

Después de muchas oposiciones a canonjías y a cátedras, don Alvaro obtuvo en I647 la canonjía doctoral de la iglesia metropolitana y luego la cátedra de Código de la Universidad de San Marcos, con exceso de más de cuatrocientos votos. Pronto logró también la cátedra de Prima de Leyes en sustitución; y en 1650 la obtuvo en propiedad, con exceso de más de doscientos votos, en concurso con celebrados universitarios.

Cuando fué virrey el conde de Alva de Liste, don Alvaro le asistió en las materias de gobierno y fué nombrado por dicho virrey protector general de indios. Una prueba evidente de la estimación que mereció fué su nombramiento como visitador del Reino de Chile en I655. El gobernador Antonio delAcuna habia sido depuesto alli por las tropas y los vecinos de Concepdión. Ibarra; inmediatamente después de llegar a Chile, inició tres procesos: uno contra el gobernador Acuña, otro contra sus cómplices los Salazar y el tercero contra las personas que habían depuesto a dicho gobernador. Muchos obstáculos le fueron puestos, inclusive por la propia Audiencia. Ello no obstante, pudo enviar presos a Lima a cuatro complicados, embargando sus bienes. Dice Alva de Liste en su "Relación": "El dicho inquisidor (Ibarra) hizo una relación ajustada para que con más facilidad se pudiera conocer la causa y le tengo por tan puntual y escrupuloso en las materias de judicatura que no faltaría en nada a la verdad". 
Se le ofreció por ese entonces la plaza de fiscal del Nuevo Reino de Granada y la de oidor de la Audiencia de Chile que no aceptó para seguir en el estado eclesiástico. Ello no impidió que ejerciera también a veces la profesión de abogado, como ocurrió en la residencia del conde de Alva de Liste, a quien defendió en virtud de un poder especial.

La Inquisición de Lima le nombró primero su familiar y su abogado defensor de presos; luego, en setiembre de 1659, inquisidor y con ese cargo actuó hasta 1669 - más tarde. Fué inquisidor severo y celebró muchos autos de fé en la capilla de San Pedro Mártir y, ya en la época del gobierno del conde de Santisteban, uno en la plaza mayor de la corte virreinal, en que salieron muchos reos.

Con el virrey conde de Lemos tuvo Ibarra una privanza aún más íntima que la que había tenido con Alba de Liste. Había entre Lemos e Ibarra claras afinidades electivas. Lemos, quejos̄o dechallat frecuentemente en el Perú hombres inteligentes de carácter débil nse sentía reconfortado con el temple de Ibarra. No conociendo al país, sus problemas y sus usos, el consejo y el aviso de Ibarra le sirvieron de luz y de ruta. Lo confesó con hidalga franqueza en reiteradas ocasiones a la Reina Gobernadora. Sin don Alvaro, dijo, no hubiera podido acabar con el feudalismo insolente de los Salcedo en Laicacota. Fué la acción contra los Salcedo, mineros riquísimos que habían hecho favores o entregado dádivas a la mayor parte de la gente importante del Virreinato, un gesto audaz que enfrentó a la autoridad política contra el poder económico.

Después de apresar y procesar a Gaspar de Salcedo, el conde de Lemos decidió ir a Puno, donde residía José de Salcedo. Muchos procuraron hacerle desistir de esa idea. 
Su vida iba a correr riesgo no sólo por la poca seguridad de la situación sino por la mala calidad del clima, los ásperos caminos, "la abundancia de yerbas y piedras venenosas", como dijo el mismo virrey en una carta. Sin embargo, partió. Muchos años hacía que un virrey del Perú no emprendía, después de haberse instalado en Lima, un viaje tan largo.

Al decidir su partida, el conde de Lemos se encontró con el problema relativo a la persona o entidad que debía dejar en el gobierno. La Recopilación de Leyes en el libro $5^{\circ}$, capítulo $3 .^{\circ}$, ley $6 .^{\circ}$ establecía bien claramente que cuando no hubiera virrey, la Audiencia ocupara su puesto; pero D. Alvaro de Ibarra, el consejero principal del conde, aclaró que en este caso habia un virrey y que, si dicha disposición se aplicaba, habrían dos gobiernos con iguales facultades y jurisdicción, lo cual resultaba un absurdo jurídico. Primero pensó el conde en formar una sala de oidores con jurisdicción limitada. Temió, empero, la repetición de las discordias por la variedad de pareceres que surgieron durante el gobierno que se formé a la muerte del conde de Santisteban. Ocupados durante las mañanas en la Audiencia y por las tardes en los acuerdos de justicia, los oidores no podían atender debidamente a los asuntos del gobierno. Existía, además, la duda si tocaba el despacho administrativo a toda la Audiencia o al oidor más antiguo. Ibarra obviaba todas las dificultades diciendo que, en el caso especial de que entonces se trataba, el virrey podía designar a la persona más conveniente. Había por fin, una circunstancia de otro carácter. Cuatro de los oidores estaban complicados con los sediciosos de Puno.

E1 conde optó por nombrar como gobernadora a la condesa. Tomó el ejemplo del conde de Lemos, su antepasado, que, siendo virrey de Nápoles, nombró por go- 
bernador a un hijo suyo, mientras él iba con una embajada de S. M.

Las facultades de la virreina gobernadora fueron restringidas. Para los negocios de guerra debía obtener el parecer y la asistencia de D. Diego Mesia, oidor de la Audiencia; para los de indios, asesorarse con D. Alvaro Hurtado; y para los de españoles, D. Diego de León Pinelo. En los asuntos más graves y arduos debía requerir el auxilio de D. Alvaro de Ibarra, dándole noticia, con su parecer, antes de ejecutar nada. Otras disposiciones contenían, además, las instrucciones del conde. Debía la condesa nombrar un secretario de Cámara. La provisión de las doctrinas, el despacho y la presentación real en los beneficios del arzobispado de Lima y de los obispados de Trujillo, Guamanga, Arequipa y Cuzco debía comunicarlo con el Inquisidor. Podría excusarse de proveer los oficios de gobierno y de guerra y de mandar pagar en la Caja Real cantidad alguna. Si venían "avisos" de España, se abrirían los cajones en el acuerdo en la forma ordinaria y mandaría recoger las cédulas, cartas y pliegos intitulados del virrey del Perú e igualmente las cartas que se escribieran de Chile, Panamá, Potosí y Quito y podría responder a las que fuesen de oficio disponiendo las materias según la calidad de ellas. Para que el comercio no parase, podría dar licencia a los dueños de bajeles que quisieran salir del Callao a los puertos donde no existiera prohibición regia. Se le mandaba que remitiera a las minas de azogue de Huancavelica Ioo,000 pesos pidiendo dinero, para continuar las labores. Los martes y viernes los dedicaría a sala de desagravio de los indios en que debía concurrir D. Juan de Padilla con los demás señores que pertenecían a ella; los miércoles por la tarde, a la junta de hacienda, donde debían concurrir D. Diego Mesía, D. Francisco Antonio Manzolo, el Fiscal de S. M. y 
D. Francisco de Colmenares, oficial real. Particular cuidado y atención debía dedicar al alivio de los indios, de acuerdo con un especial encargo de S. M. La puntualidad en el cobro de los tributos y el castigo de los delitos debían ser, en este ramo, sus miras (I).

Los servicios de Ibarra no quedaron reducidos a este episodio. Declaró el virrey terminantemente que solamente a Ibarra se debió la prontitud del socorro a Porto Bello; solamente a él, las disposiciones para la pacificación de Chile, para los ahorros en el presidio de Valdivia y para el arreglo de los asuntos de Huancavelica. (2)

En virtud de los grandes elogios y recomendaciones de Lemos que coincidian, además, con despachos de otros virreyes anteriores, Ibarra recibió una serie de cargos y de honores. Uno de ellos fué nada menos que el nombramiento de oidor más antiguo de la Audiencia de Lima y visitador de ella, con plaza de miembro delConsejo de Indias cuando acabara sugvisitaciLallcédulavrespectiva llegó en el aviso del 23 de agosto de I669; y el 2 de setiembre hubo carreras de caballos en la calle donde Ibarra vivía. (3)

La visita de la Audiencia de Lima no era sino la continuación de la que empezara D. Juan Cornejo, llegado es-

(1) Las instruceiones del conde a la condesa tienen fecha 30 de mayo de 1688. La carta en que comunica su nombramiento y las razones de él, es de 17 de diciembre de 1688. Todo esto, en Audiencia de Lima, legajo 67. Archivo de Indias.

Por disposición real quedó constancia de que liabía parecido bien lo obrado por la condesa en ausencia del conde. La aprobación antedicha fué motivo de un despacho particular al Virrey con una advertencia severa: "Pero para lo de adelante se le advierte que, euando por ausencia, enfermedad, impedimento y otras causas que previenen las cédulas y órdenes que están dadas, hubiere de tener quien gobierne aquellas provincias, se observa puntualmente lo que en ellas está dispuesto".

(2) Archivo de Indias, Audiencia de Lima, legajo No. 68.

(3) Mugaburu, "Diario de Lima". 
pecialmente de España para ella. En vista de las excesivas dilaciones de Cornejo, se había llegado a expedir una cédula en 1666 dando por terminada dicha visita y ordenando a Cornejo que se embarcara para España con todos los papeles que había llegado a reunir. Cornejo murió en el viaje, en I667; perc sus papeles llegaron al Consejo. Se trató entonces de nombrar algún magistrado de España; pero unos se negaron por la dilación de los viajes o pidieron compensaciones excesivas.

La comisión dada a Ibarra (y que éste aceptó no sin dejar constancia de que hubiera preferido seguir en el estado eclesiástico) en vez de tener un carácter general, aludía concretamente a los oidores de Lima que resultaban inculpados, según los papeles de Cornejo. Ibarra tomó este asunto, como de costumbre, muy en serio.

Las inculpaciones al oidor D. Francisco Sarmiento de Mendoza eran gravísinas. Durante la época en que gobernara Potosí, Sarmiento de Mendoza había tenido negocios con mineros y curacas, interviniendo en ventas de indios y en el envío de ellos con cadenas fuera de Potosí. Parecía comprobado, adénás, que cohechó a suvisucesor cuando llegó el momento de que éste le tomara la residencia. No había sido deshecha, por último la acusación de que mató con veneno al visitador de Charcas D. Francisco Nestares Marin. Ibarra llegó a pronunciar sentencia desfavorable para Sarmiento de Mendoza y de acuerdo con ella, procedió al embargo de sus bienes. Condenado además, Sarmiento de Mendoza a vivir lejos de Lima mientras preparaba su viaje a España, dilató el cumplimiento de esta parte de la sentencia; pero a poce murió en Huaura. (4)

(4) Los antecedentes de Sarmiento de Gamboa, en el legajo No. 280, Audiencia de Lima, Archivo de Indias Las instruciones a Ibarra, en el legajo No. 574. 
Mejor librado salió otro de los oidores acusados, D. Tomás Berjón de Caviedes. Había ocupado Berjón de Caviedes, en su calidad de oidor de la Audiencia de Lima, el gobierno del asiento minero de Huancavelica. Ibarra, al realizar su visita, le halló culpable, con otras personas más, de la mala distribución de los 232,000 pesos que el virrey conde de Santisteban remitiera a Huancavelica como socorro para los mineros y pago de los llamados indios "cotabambas". (5) Cómplice de Berjón de Caviedes resultó su esposa, a quien se acusaba de haber organizado y dirigido casas de juego. (6) Apenas llegó el conde Lemos al Callao, le visitó Berjón de Caviedes; pero tantas fueron su zalemas que el conde empezó a desconfiar. Conocedor el conde de que Berjón de Caviedes hablaba hasta en las calles contra Ibarra y que personas respetables come el obispo de La Paz, Martín de Montalvo, tomaba en cuenta esa maledicencia, decidió aclarar todo y pidió a D. Alvaro que una noche acudiese a Palacio, disponiendo que esa misma noche fueran a verle el osbispo y el propio Berjón. En la entrevista Ibarra enumeró con precisióntlos cargos existentes y Berjón sólo repuso a voces Josecentrtradijoli El buenoo del obispo quedó convencido. $Y$ el virrey se lamentó que no estuviera entre su facultades la de mandar ahorcar a Berjón y a otros ladrones de alta calidad. Sin embargo, Berjón pudo dirigirse a España y utilizar valiosas influencias en su favor, consiguiendo al fin ser repuesto en su plaza de oidor.

El rigor de Ibarra no sólo se limitó a los oidores acusados; se extendió también a los que se encontraban en ejercicio. Llegó a colectar una multa a D. Bernardo de Iturrizara, D. Bartolomé de Salazar, D. Fernando de Velasco, D. Die-

(5) Llamábase "cotabambas" a los indios que no eran mitayos y que se alquilaban para determinados trabajos en aquellas minas.

(6) "Cuadernos de la vista de D. Alvaro do Tbarra contra D. Tomás Berjón y demás culpados", Audiencia de Lima, legajo No. 271. 
go Messia, y D. Pedro González de Guemes, por haber aceptado falsas imputaciones acerca del título de escribano ante quien había actuado el visitador Cornejo. González de Guemes se hallaba en Santa Fé cuando dicho escribano presentó sus docurinentos y, sin embargo, votó contra él; la multa en su caso ascendió a 500 pesos, mientras que la de los demás limitóse a 300 pesos. (7)

Es muy interesante el proceso que Ibarra inició contra el oidor Velasco. En cierta ocasión, con motivo de disturbios producidos entre los indios de la provincia de Cajatambo por los malos tratos del administrador del obraje de San Juan de Lurín, Velasco fué enviado en comisión a dicha provincia. Ya el corregidor había logrado reducir a los indios cuando llegó Velasco; pero éste mandó apresar a doce de los principales. Ante tal noticia las labores volvieron a interrumpirse y se conmovieron todos los pueblos aledaños. Más de seiscientos indios llegaron a reunirse en actitud airada, pretendiendo quemar la casa donde moraba Velasco. Nervioso, éste ordenó matar a los presos. Cuatro de ellos lograron huir y la ordenilsóló fúe ejecutadâ. conrecho, sin darles lugar a la confesión judicial ni sạcramental.Ibarra halló a Velasco culpable de estas muertes y pidió que fuera castigado, aunque moderadamente en vista de la turbación con que obró. La sala de justicia del Consejo de Indias, de acuerdo con lo expuesto por Ibarra, condenó a Velasco a cuatro años de destierro de Lima, en veinte leguas del contorno de dicha ciudad, más dos años de suspensión en el ejercicio de su plaza y mil pesos de multa repartidos en misas para los indios muertos. Al ser llevada esta decisión a la firma de la Reina Gobernadora, ella se negó a firmarla considerando que la gravedad del asunto era extraordinaria y que deba abrirse el juicio, procediéndose contra el oidor culpable conforme a

(7) Audiencia de Lima, legajo No. 574. 
derecho. El Consejo de Indias deliberó y representó en contra de lo exigido por la Reina. Siempre la autoridad real se había conformado con las decisiones del Consejo sobre casos como éste. El hecho de abrir nuevo juicio implicaría una enorme dilación de tiempo, pues eran necesarios la acusación, el traslado, el poner la causa a prueba y la sentencia de vista y de revista, todo ello dentro de los términos ordinarios de ultramar. El oidor Velasco era, además, hombre de edad muy avanzada. Ante estas y otras razones, la Reina se conformó, firmando la decisión de la Sala de Justicia del Consejo. (8)

Durante los años de gobierno del conde de Lemos, el arzobispo de Lima D. Pedro de Villagomez sufría todas las limitaciones impuestas por su avanzada edad. Lemos recomendó a Ibarra como coadjutor del arzobispado de Lima. Cuando Villagomez murió, surgió la candidatura de Ibarra. El Cabildo de Lima lo recomendó calurosamente; pero el nombramiento no llegó a producirse.

Con motivo del fallecimiento del conde de Lemos, Ibarra presidió la Audiencia gobernadora y fué capitán general de estos réinose Con el sucesor dertemos, el conde de Castellar, Ibarra continuó ejerciendo sus funciones de consejero e inspirador. A esta época pertenece su intervención en el gobierne de la Universidad de San Marcos.

El problema fundamental que apasionaba en la Universidad de Lima por ese entonces, era el de la provisión de las cátedras. Este problema tenía dos aspectos fundamentales: una de carácter general, sobre las personas o

(8) ConsuIta del Consejo de Indias, 24 de setiembre de 1674. Archivo de Indias, Audiencia de Lima, legajo No. 11. 
entidades que debían otorgarlas y otro que, concretamente, atañía a las cátedras de Artes y al Colegio de San Martín.

Acostumbrábase entonces hacer la provisión por voto del claustro de doctores y maestros de la Universidad en las oposiciones acostumbradas, o por elección del virrey el arzobispo y el provincial en tres cátedras (Prima, Vísperas y. Nona de Teología) señaladas para religiosos de la orden de Santo Domingo.

La Universidad tuvo la pacífica posesión en la propiedad de sus cátedras, por lo general; pero hubo de conformarse siempre con las disposiciones de los virreyes. Ya gobernando el virrey D. García Hurtado de Mendoza, segundo marqués de Cañete, la cátedra de Prima de Teología fué dada por él al P. Esteban de Avila, S. J., quien la leyó durante seis años. Reemplazóle el P. Juan Pérez Menacho por disposición del virrey D. Luis de Velasco, regentándola durante cinco años. En ese tiempo, sólo había dos cátedras de Artes y una de ellas fué dada también a sacerdotes de la Compañía de Jesús (los PP. Andrés Hernández, Francisco Perlin y Christian García). Con Fas rentas de Primas de Teología y la de Aftes fueron hechos Pos Generales (salones de actos) y ahorró la Universidad buena suma de dinero en el espacio de once años en que dichas cátedras estuvieron a cargo de la Compañía de Jesús. Esta acabó por renunciarlas irrevocablemente, aunque la Universidad ofreció varias veces a Pérez de Menacho la de Prima, sin resultado.

El virrey príncipe de Esquilache resolvió que volviese la Compañía de Jesús a la Universidad; pero entonces la única Prima que había en Teología estaba ya dignamente ocupada. Fué entonces cuando instituyó otra de Prima, sin señalarle renta porque la había de leer la Compañía, y nombró para ella al P. Juan Pérez de Menacho. Contaba entonces la Universidad tres cátedras de Artes de oposición y concurso 
general; y el virrey dió la primera que vacó a la Compañía en la persona del P. Francisco de Aguayo, aplicando a la Universidad la renta de dicha cátedra para instituír la de Código. $Y$ al cabo de algún tiempo, la Compañía volvió a renunciar ambas cátedras. (9)

No obstante estos casos y otros más, lo común era que la provisión de cátedras fuese hecha mediante concurso. La ciudad entera se interesaba en la Universidad con tal motivo. D. Felipe Pardo y Aliaga lo recordaba enmedio de los tumultos políticos de la República:

Aunque gruñan severos Aristarcos yo prefiero a estos tiempos que dán grima, aquellos tiempos en barullo parcos en que tan sólo se agitaba Lima cuando elegía su Rector, San Marcos o votaba una cátedra de Prima.

Las cátedras universitarias conferían entonces a sus poseedores importanciacintelectual y social. Su duración era vitalicia. A pesar de la obligatoriedad de los concursos, ocurría a veces que los virreyes optaban por "depositar" las cátedras vacantes en catedráticos en ejercicio, durante un período de tiempo variable. Era corriente que quienes tenían ya una cátedra, aspiraran a otra mejor. En el concurso, se juzgaba no sólo la lucidez de las pruebas, sino el tiempo de servicios y se daba preferencia (salvo que influyeran circunstancias especiales) a la antigüedad. Salvo también casos de excepción, al que perdía por pocos votos una cátedra importante, la de Prima de Cánones por ejemplo, se buscaba la manera de darle otra, por ejemplo, en ese supuesto, la de Prima de Leyes.

(9) Informe de la Universidad al Rey, 18 de setiembre de $167 \overline{7} . \overline{A u}-$ diencia de Lima, legajo No. 17. 
Cuando D. Diego de León Pinelo dejó su cátedra de Prima de Cánones para ocupar el cargo de Protector de Indios, vinieron las oposiciones de ella y con motivo de haberla obtenido D. José de Reyes, catedrático de Decreto, hubo disturbios con muertos y heridos. Intervino en la Universidad el Visitador del Virreinato don Juan Cornejo y, con fecha I 5 de noviembre de 1665 reformó el sistema de provisión de cátedras. Consistió esta reforma en la reducción del número de votos y en la prohibición de vítores y acompañamientos a los catedráticos triunfantes, por ser manifestaciones en que se lucían armas. En lo que respecta a la reducción del número de votos se inspiró Cornejo en lo que había dispuesto para la Universidad de Méjico, el Visitador de aquel Virreinato D. Juan de Palafox. Los doctores y maestros de todas las órdenes religiosas continuaron con el derecho de votar; pero los doctores con seis votos solamente $\mathrm{y}$ los maestros con otros seis. Los estudiantes de la cátedra en cuestión también continuaron con ese derecho; pero sólo en el número de diez, contando los más antiguos en cursos y en grado. Los bachilleres quedaron, en cambio, sin voto. (10)

La Universidađgreclanoilcontra estaśmedidas con fecha 4 de diciembre de i666. Una cédula expedida por la Reina Gobernadora ratificó el derecho de voto de los bachilleres y volvió a recomendar que las Constituciones no fueran alteradas por urgentes que ello pareciera, "pues es regalía reservada al Consejo de Indias". (26 de setiembre de 1669. ( I I)

Según el informe emitido años después por la Audiencia de Lima, Cornejo, a pesar de las protestas de la Universidad, había hecho bien, al quitar los votos a los bachilleres. Con motivo de las vacantes de las cátedras, los estu-

(10) Las reformas de Cornejo, en Audiencia de Lima, legajo No. 337. (11) Audiencia de Lima, legajo No. 72. 
diantes solían esperar a graduarse a costa de los opositores, haciéndoles muchas estafas de dinero durante los cinco años en que gozaban del derecho de votar. Además, los bachilleres aumentaban en exceso el número de los sufragantes y las elecciones terminaban siempre de noche, con disturbios, heridas y muertes. (I2)

A pesar de las reformas de Cornejo, "los actos literarios" continuaron siendo "sediciones armadas" según la enérgica expresión del conde de Lemos. El claustro se componía de más de doscientos doctores y maestros: cada doctor siendo de la Facultad, tenía seis votos, los maestros cuatro, los médicos dos, y los estudiantes uno, cuyo número no pasaba de sesenta. La cátedra salía generalmente "por quien quiere el doctor que más mano tiene o por el sujeto que puede reducir asi por malos medios dos o tres religiones, dado el excesivo numero de miembros que los componen". "Para provisiones, señora, se alborota toda la ciudad, se mezclan los arzobispos, se interesa la Inquisición y se hacen tantas y tan grandes maldades que no sólo lo paga la República sino el servicio de Dios, dándose las doctrinas a incapaces por atraer los votos delos religiosos, siendo estos tan tiranos en vender los suyos, que deja rico a un convento la provisión de una cátedra". (I3)

Durante el gobierno del conde de Lemos, la provisión de toda clase de cátedras fué suspendida hasta que S. M. señalara nuevas formas de votación. La causa de tan radical decisión estuvo en lo que ocurrió en Lima el 8 de marzo de I670. Don Gregorio Rojas, opositor a la cátedra de Prima de Leyes, por muerte del Dr. Alonso Coronado, salió entre 9 y ro de la noche de la Universidad, de presidir un acto de

(12) Informe de la Audiencia, 9 de abril de 1673. Audiencia de Lima, legajo No. 73.

(13) Carta del Virrey conde de Castellar, sucesor del conde de Lemos. A. de I. Audiencia de Lima, legajo No. 74 . 
licenciado y al pasar por la esquina de la casa de un opositor, le acometieron con espadas y rodelas, sumándose a los atacantes muchos mulatos y negros con piedras. Algunos colegiales de San Martín que iban acompañando al que se venía de examinar, resultaron heridos y maltratados. "Como la plebe de esta ciudad es de gente ociosa (añadía, por su cuenta, el virrey) en que concurren mulatos, mestizos y españoles, se mezclan entre los estudiantes". (I4)

El nudo del problema universitario estaba entonces en el voto de las órdenes religiosas para dichas provisiones. Los clérigos teólogos veíanse imposibilitados de alcanzar las cátedras de Teología y Artes por el número enorme de religiosos que intervenían en la Universidad. Con tal motivo, optaban por estudiar Cánones y Leyes. Con los estudiantes del Colegio de San Felipe, destinado desde su fundación, a los Cánones, realmente nada ocurría de grave. En cuanto a los del Colegio Seminario de Santo Toribio, por la opción que tenían, imitaban el ejemplo de San Felipe. El Colegio de San Martín, en cambio, por su fundación, debía estimular el cultivo de las Artès ẏ dé dacTeología ey losssacerdotes de la Compañía de Jesús, a pesarideitodos sussesfuerzos, no podían reducir entonces a los estudiantes a dichas especializaciones.

El cuadro de los estudiantes a mediados del siglo XVII era, pues, el siguiente: Los colegiales de San Felipe cursaban Derecho. Los del Colegio Seminario eran, a lo sumo, cuatro o cinco en la Universidad y algún año menos por acudir tan sólo en el número necesario para el buen servicio y asistencia de la catedral; y estos optaban por el Derecho y raro o ninguno era el que se decidía por Artes o Teología. Por algún tiempo, del mismo Colegio de San Martín un alumno

(14) Carta del conde de Lemos, 11 de marzo de 1670. Audiencia de Lima, legajo No. 72 . 
tan sólo cursó Metafísica y dos Teología de los lógicos. Para evitar la afluencia hacia el Derecho por parte de los colegiales de San Martín, los Visitadores, de acuerdo con los Generales, se habían visto obligados a valerse de los preceptos de santa obediencia. Sólo la presión o la necesidad imprescindible de vivir en el Colegio podían hacer aceptar a los colegiales los estudios de Artes y Teología.

La causa de tan patente desvío estaba en la imposibilidad de conseguir las cátedras donde poder lucir los estudios y el ingenio. En saliendo un religioso a oposiciones en este campo, la abundancia de estudiantes, doctores y maestros religiosos, le daba un número considerable de votos. El clérigo o colegial secular, en cambio, entraba muy solo y tenía que buscar desde el primer voto. Aún el canónigo o dignidad de la catedral y no simplemente el humilde colegial o el anónimo presbítero, hacían un gesto de temeridad al querer la cátedra. Así era como entre las cátedras de Teología, sóla una estaba en poder de un colegial que había sido de San Martín, por disposición del Virrey conde de Santisteban. De las tres cátedrasidetArtes, dos tenía tasclerecía. Una fué dada por el Virrey,estorbandbila oacción de las órdenes religiosas y la otra provino de que, por raro accidente, sólo hicieron oposición dos sujetos seculares y veinte años hacía que el catedrático la leía, sin poder, en todo ese tiempo, ascender a catedrático de Teología. Cuando los religiosos que ostentaban cátedras de Teología y la restante de Artes, todavía eran cursantes y algunos estaban todavía en los estudios de Latinidad, ya los dos de la clerecía que leían Artes, con ser tan capaces, eran opositores a cátedras.

Los buenos estudios de Teologa dependían de los de Artes. Era necesaria la Teología con el objeto de que hubiese hombres doctos para la provisión de curatos, instrucción religiosa de los indios y lucido desempeño de las cátedras. El 
Colegio de San Martín, por su erección, debía ocuparse de estos estudios, y que fuera del tiempo destinado a las clases en la Universidad, hacía llevar a sus discípulos vida en comunidad, dedicada a ejercicios; fué por todas estas razones que pidió para sí una de las cátedras de Artes. (I5)

En la Universidad de Salananca, modelo de la de Lima, no había ejemplos para la pretensión del Colegio de San Martín. Dos circunstancias divergentes explicaban esta situación. En todos los colegios de Salamanca había opción para estudiar Teología o Leyes, mientras que el Colegio de San Martín era el único que en Lima acogía los de Artes y Teología obligatoriamente. Esta como primera diferencia. Además, la provisión de cátedras en Salamanca no se hacía entonces por votos de los doctores y estudiantes como en $\mathrm{Li}$ ma, sino por elección del Real Consejo.

Para quienes miraban el problema universitario sólo en su fase más polémica, lo fundamental era la provisión de cátedras. En estas como en muchas otras cosas, mostró, sin embargo, mirada penetrante y criterio de estadista don Alvaro de Ibarra, que, poiresta época,presentîa.al Virrey conde de Lemos quince puntos sobreilabéforma universitaria. ( I6) Allí estaban comprendidos no sólo las elecciones y provisiones en las que Ibarra quiso imponer el principio de autoridad, sino otros asuntos menos ruidosos pero no menos fundamentales: la urgencia de limitar el número de estudiantes, ampliado en demasía por un contraproducente espíritu de lenidad; la necesidad de velar por la eficiencia de los ca-

(15) Carta del Rector Gerónimo Hurtado del Aguila, fechada el 16 de junio de 1666. A. de I. Audiencia de Lima, legajo No. 72.

Comunicación de Manuel de Villabona, S. J., Procurador General de las Provincias de Fndias y otros documentos al respecto. Audiencia de Lima, legajo No. 17. Ver también las cartas del Conde de Lemos al respecto, idem. No. 69.

(16) Resumidos y comentados en la citada carta del Conde de Lemos, Audiencia de Lima, legajo No. 72. 
tedráticos; 1a justicia de una vigilancia sobre las llamadas incorporaciones de grado, susceptibles de corruptelas. Pedía, fundamentalmente, Ibarra: Que la elección de Rector se realizara cada dos años, sin reelección. Las cédulas de I 3 de mayo de I 590 y 29 de enero de 1603 y las constituciones de la Universidad, disponían que dicha elección fuera anual, alternando clérigos y legos y que existiera el derecho de reelección. Que la elección se hiciese sin alternativa, en doctores graduados en Teología, Cánones y Leyes, excluyendo médicos, artistas y religiosos. Por la constitución sexta de la Universidad, eran admitidos los maestros en Artes, así como los médicos y religiosos.

Que no concurrieran a los clánstros los doctores y maestros, bastando el Rector, el Vice-Rector, el Conciliario Mayor y los catedráticos, excusándose así la confusión para resolver las materias de gobiemo y hacienda.

Que los Padres de la Compañía de Jesís diesen cédulas de aprobación a los estudiantes que pasaban de Gramática a oir las cátedras de las Eacultàues, porque algunos eran mestizos cuarterones de mulatos e inquietos y recibian dichas cédulas precisamente para que ingresando ellos a la Universidad, los Padres quedaran más tranquilos. Convendría que los catedráticos de Prima de todas las Facultades volvieran a examinar a dichos estudiantes en votación secreta, con notas de aprobado o reprobado y que no admitieran a mestizos, zambos, mulatos y cuarterones e hiciesen previo juramento de no aprobar sino a los aptos. La constitución 23 de la Universidad sólo excluía a los penitenciados por el Santo Oficio o sus padres y abuelos notados de infamia. Los mestizos podían recibir órdenes (Solórzano, libro $4 .^{\circ}$, capítulo 20 ); pero sólo si poseían las calidades de virtud y letras prescritas por el Concilio de Trento y en número restringido (Cédulas de I 8 
de noviembre de I566, I3 de noveimbre de 1577 y 5 de noviembre de I578).

Que se aplicara la cátedra de Escritura a la Orden de San Agustin; la de Visperas de Teología a la orden Mercedaria; la de Prima y la Nona y las tres de Artes al clero. Pero debía haber por lo menos dos opositores en las cátedras otorgadas a una orden réligiosa; y sinó entregarlas a la oposición comin del clero secular y de las religiones.

Que se examinara a los religiosos de Santo Domingo antes de que obtuviesen las cátedras adjudicadas a esa orden, intentando paliar, mediante las oposiciones, la decadencia que parecía aquejarla. La cédula de Ir de abril de 1643 y la ley 32 del título 22 libro I ordenaban que para ser elección de los religiosos catedráticos se reunieran el Virrey, el arzobispo, el oidor más antiguo y el provincial de la Orden, o el prior en caso de ausencia del provincial, para hacer el nombramiento sin examen.

Que para excusar sobornos (pues muchos se graduaban para entablar capellanias con sus votos), se mudara la forma de votar las cátedras. Proponia Tbarra que votaran el Virrey. el arzobispo, los oidores, alcaldes y fiscales del gremio de la Liniversidad, los inquisiäores y el fiscal del Santo Oficio, las dignidades de la Catedral, los provinciales de Santo Domingo, San Agustín y la Merced si eran doctores o maestros y el Rector y catedráticos en ejercicio y nadie más. Disponían la constitución 92 de la Universidad la cédula de 9 de mayo de I603 y la ley 39 N. 22 , libro I. ${ }^{\circ}$, que las cátedras fueran provistas por oposición y mediante el voto de los estudiantes. No habiendo cien votos debían entrar a votar los doctores y maestros. La cédula de 14 de julio de I6I 8 y la ley 45 mandaban que los Virreyes nombrasen personas especiales para averiguar y castigar a los que sobornaran y fuesen sobornados. Esta disposición parecía insuficiente. 
Que fuese reglamentada la incorporación de grados. Los estudiantes que apenas sabían latín viajaban a España para volver graduados de O'suna y otras Universidades de poco rigor en sus exámenes. Debía, por lo tanto, mandarse que la incorporación se redujera a los grados de doctor y maestro después de haberse obtenido en Lima el de licenciado, por el riguroso examen que en esta ciudad se hacía.

Que los puntos del grado de licenciado sean de veinte y cuatro horas la lectura y argumentos, empezando a las tres de la tarde y con votación secreta. (Todo esto hallábase ya en las provisiones escritas).

Como había fraude en la toma de puntos y convenía la asistencia estricta de los catedráticos examinadores, los ausentes debian perder las propinas, acrecentándolas quienes concurrieran. El Rey había mandado que los ministros de la Real Audiencia fueran examinadores supernumerarios en Cánones y Leyes; y este gasto podía excusarse con que los ministros y catedráticos fuesen examinadores en todo caso, y despiués ientrasen lôs doctores más antignos hasta el numero de diez y seis.

Que los puntos para leer, por excusar inconvenientes, se ha de mandar que sean tomados a las 3 de la tarde y la misma hora lean los graduados al día siguiente.

Que el opositor que tuviera juntas de legos y estudiantes en su casa, pierda el derecho a la cátedra porque esa ha sido una de las causas de las muertes, alborotos y escándalos.

Sin embargo, la cuestión de la provisión de las cátedras era-la cuestión palpitante en la Universidad de Lima, y resolverla quisieron las cédulas de 26 de mayo de $\mathbf{1} 676$ y 5 de marzo de 1684. 'Ellas caen, en realidad fuera del ámbito de tiempo a que el presente trabajo se contrae; pero 
vienen a complementar y a aclarar problemas ya planteados a mediados del siglo XVII.

La cédula de 26 de mayo de 1676 llegó a recoger, no en detalle pero sí en parte, las sugestiones de Ibarra. (I7) Dispuso ella que fueran votantes en la provisión de cátedras: el arzobispo, el oidor más antiguo de la Audiencia, el inquisidor más antiguo, el Rector, el maestre escuela, el dean de la Iglesia metropolitana, el catedrático de Prima de la Facultad a la cual pertenecía la cátedra en cuestión el doctor más antiguo de dicha Facultad; y si estaba vaco el decanato, la dignidad más inmediata, y si el Rector era el doctor más antiguo, el que fuera siguiente en antigüedad. Si se trataba de proveer la cátedra de Prima, debía intervenir el inmediato si es que no era opositor. La votación debía hacerse en escrutinio secreto, con dos cántaros, uno para el nombre del elegido y otro para las cédulas o habas en que no se daba el voto. Las juntas para la votación debían tener lugar en la casa del arzobispo, su presidente; y el oidor más antiguo debía preceder al Inquisidor en el asiento.

Más tarde, Bidénticoseprincipios @eterminaron reformas en las Univērsidades den SalamancarsValladolid y Alcalá. Así, Ibarra influyó sobre todo el régimen universitario español.

La Universidad de San Marcos suplicó de esta cédula. En primer lugar, ella no había sido oída antes de ser privada del derecho y posesión de que antes disfrutaba. En segundo lugar, las injusticias y disturbios habian sido (según ella) grandemente exageradas. $Y$, en cambio, el remedio propuesto podía traer como consecuencia la destrucción de los estudios. En todo caso (decía la Universidad in-

(17) Las proposiciones de Ibarra fueron remitidas al Virrey que era ya entonces el conde de Castellar, para que se formase una junta compuesta por el Rector, el maestre escuela, un doctor y tres oidores y diera un dictamen al respecto (13 de junio de 1675). Audiencia de Lima, legajo No. 72. 
sistiendo mucho en este concepto) el exceso de algunos de los estudiantes no debía recaer sobre el común de la Universidad, sus graduandos y doctores que, de ordinario, pasaban de 230 sujetos de toda edad, los más eclesiásticos. En suma, lo que la Universidad pedía era la subsistencia de las reformas de Don Juan Cornejo.

La cédula de 5 de marzo de 1684 , reformando la de I676, dispuso la intervención de veinte y nueve sujetos para la dación de las cátedras. El Rector y el maestre escuela debían intervenir en todo caso. Si la cátedra era de Teología, Cánones o Leyes, se requería la presencia y el voto de todos los catedráticos graduados de una y otra $\mathrm{Fa}$ cultad, de los doctores más antiguos de la Facultad pertitinente hasta el número de veinte y cinco y de cuatro colegiales de San Martín, los cursantes más antiguos en la matrícula de la Facultad respectiva.

Tratándose de cátedras de Artes o Medicina, habían, de actuar los catedráticos graduados de ambas Facultades, los de Teología, Gánones y Leyes, los doctores y maestros más antiguos y los cuatro colegiales más antiguos. Para la cátedra de Lengua, eran requeridos todos los catedráticos graduados de la Universidad. 'En el caso de la cátedra de Matemáticas, se prescribía la intervención de los doctores más antiguos y de cuatro colegiales. El derecho de antigüedad pasaba a los doctores más inmediatos, si se presentaba la incompatibilidad por ser el doctor más antiguo uno de los opositores. Siempre los electores debían ser veinte y nueve, y de ellos cuatro colegiales, con la sola excepción del caso de que asistieran entre los oidores graduados en la Universidad y quisiesen votar.

La cédula del 4 de julio de I687, válida para Teología, Cánones, Leyes, Artes, Medicina, Matemáticas y Lengua 
Indígena, volvió con algunas modificaciones al régimen antiguo. Debían, según ella, votar el Rector, el maestre escuela, todos los catedráticos propietarios, graduados de doctores, en todas las cátedras. Los doctores y maestros no catedráticos debían votar cada uno en su Facultad. Los teólogos en Teología y Artes por ser aquella Facultad superior que suponía el grado de doctor en Filosofía; los doctores graduados en Cánones o en Leyes, debían votar así en Cánones como en Leyes por ser de una misma Facultad el Derecho Civil y el Canónico; los doctores médicos, en Artes y Medicina; los graduados de maestros en Artes votarían en Artes y Medicina porque se correspondían y la una era necesaria para la otra. Debían votar también los tres colegios, de San Felipe, San Martín y Santo Toribio, el primero con tres votos, el segundo con cuatro por tener más colegiales y el tercero con dos; votos que serían sorteados el mismo día de la votación entrando en el cántaro los nombres de los estudiantes de aquella Facultad a la cual perteneciera la cátedra. Del gremio de los manteístas votarían diez bachilleres y veinte cursantes en cánones y Leyes: cinco bachilleres y quince cursantes en Teología; cinco bachilleres y veinte cursantes en Artes; y en cuanto a Medicina, por ser pocos los concursantes, diez bachilleres y cinco cursantes. Estos votos serían sorteados entre los presentes en el claustro de la Universidad el día de la votación. En las cátedras de Matemáticas y Lengua Indígena, en las cuales no habían grados de doctores ni maestros, votarían el Rector, el maestre escuela y todos los catedráticos propietarios de todas las cátedras que fueran graduados y todos los cursantes, por ser muy reducido el número de estos. Ninguna persona debía tener más de un voto y los bachilleres 
gozarían del suyo tan sólo por dos años. (I8) Esta cédula llegó a tener más larga aplicación que las anteriores.

A medida de que fué avanzando el siglo XVII, la Universidad comenzó a aumentar las cátedras pertenecientes a una orden religiosa determinada. Con este crecimiento dió una nueva fisonomía a sus estudios y a su influencia La orden de Santo Domingo contó desde I643 con la cátedra de Prima de Teología, dedicada a la doctrina de Santo Tomás. Anteriormente, ya en 1637, D. Feliciano de la Vega, Arzobispo de Méjico, había donado 600 pesos a la comunidad dominicana para la enseñanza de Prima de Teología Moral. Fué en I 695 cuando se creó la de Filosofía, sustentada con 500 pesos, réditos de un correspondiente principal y dada al Fray Jorge Carrasco hasta su muerte.

La orden de San Francisco poseyó desde izor la de Prima del doctor Escoto y desde i724 la de Vísperas, ambas $\sin$ rentas. Sólo en I 692 queda dispuesto que la orden de San Agustín lea res cátedras: Prima y Vísperas de Dogmas de su santoy yna del Maestra de las Sentencias. Fué en i666 ctrando doñai María@AñarSamiento, Marquesa de Casares viuda del capitán Andrés de Almoguera, habiendo perdido en oposiciones la cátedra de Nona de Teología su hijo el Mr. Fr. Sebastián de Pastrana de la orden de la Merced, catedrático de Artes muy antiguo, decidió realizar una donación para fundar una cátedra de Doctrinas de Santo Tomás con la condición de que el primer catedrático fuese el susodicho Pastrana y de que a su muerte le sucediera otro hijo de la misma señora y pasase después dicha cátedra a la Orden de la Merced. Más tarde se extinguió esta renta y la orden Mercedaria quedó sin cátedra

(18) Todos estos documentos y sus antecedentes en Audiencia de Lima, legajo No. 337. 
hasta 1726 en que se fundó la de Doctrina de Francisco Suárez.

A mediados del siglo XVIII también consiguieron cátedras propias las comunidades de la Buena Muerte y de los Mínimos de San Francisco de Padua. (I9)

Inquisidor y oidor, sacerdote, maestro y magistrado, don Alvaro de Ibarra reunió, pues, las más respetadas profesiones de su tiempo. Dueño de una mente clara, de una erudición abundante y de conocimientos exactos sobre su país y sus compatriotas, poseyó, al mismo tiempo, capacidad para la acción, gusto y constancia para los asuntos prácticos y energía acerada en el cumplimiento de sus decisiones, prescindiendo del temor a las resistencias que ellas podían causarle. Llamáronle sus enemigos hombre soberbio y ambicioso; no le pudieron negar, sin embargo, experiencia, celo y entereza.

Pero es en otro aspecto de su actuación que Ibarra parece representar un personaje más común: en el hecho de haber sido en verdad "el poder detrás del trono". Criollos así, inteligentes y cultos hubo en verdad siempre al lado de los Virreyes. El papel que desempeñaron tiene, en suma, alguna semejanza con el de muchos civiles-abogados o sacerdotes-al lado de los caudillos militares durante la primera época republicana, como sus ministros, secretarios, consejeros y hasta redactores de proclamas, decretos y manifiestos. Y la semejanza también se extiende a la cir-

(19) "Historia de la Universidad de San Marcos" por D. José de Baquíjano y Carrillo. "Mercurio Peruano", Lima, 1791, vol. II. El expediente de la Orden de Santo Domingo sobre la fundación Pastrana, en el A. de I., legajo at., Lima, 337. 
cunstancia, en ambos casos realizada, de haber sido esa colaboración más tarde casi siempre olvidada.

No estuvo, sin embargo la muerte de don Alvaro de Ibarra a la altura de las posiciones que su vida alcanzó. Consigna la noticia Mugaburu, el cronista de Lima en aquella época, que varias veces anota la significación de don Alvaro durante el gobierno de Lemos: carreras de caballos en su calle el 23 de agosto de 1669 , con motivo de haber llegado la cédula de oidor más antiguo y visitador de la Audiencia y oidor del Consejo de Indias cuando acabara la visita; arcos y colgaduras en las calles "como jamás se había visto en la ciudjed" al tomar posesión de su cargo; constantes visitas a su chácara del Virrey y la virreina con criados y damas; honores y ceremonias al ser nombrado capitán general como oidor más antiguo y visitador de la Audiencia Gobernadora. Pero más, adelante dice: "Sábado i9 de enero de 1675 años murió el señor don Alvaro de Ibarra, y domingo a las seis de la tarde fué enterrado en la iglesia de la Compañía de Jesús desta ciudad de Lima. Y en su entierro no se halló el señoe Virrey por estar en el Callao al despacho de ar̃madap ni tampóco fué en el entierro el Cabildo eclesiástico por ciertas diferencias, que después de muerto se vengaron del difunto. $Y$ siendo hijo de la tierra y habiendo ocupado tantos puestos honoríficos que le dó S. M., nada le valió a la muerte, y así no hay sino servir a N. S. Jesucristo, que todo lo demás es burla". 